This item was submitted to Loughborough's Research Repository by the author.

Items in Figshare are protected by copyright, with all rights reserved, unless otherwise indicated.

\title{
Insights into ethanol electro-oxidation over solvated Pt(1 00 ): Origin of selectivity and kinetics revealed by DFT
}

PLEASE CITE THE PUBLISHED VERSION

https://doi.org/10.1016/j.apsusc.2020.147505

\section{PUBLISHER}

Elsevier BV

\section{VERSION}

AM (Accepted Manuscript)

\section{PUBLISHER STATEMENT}

This paper was accepted for publication in the journal Applied Surface Science and the definitive published version is available at https://doi.org/10.1016/j.apsusc.2020.147505.

\section{LICENCE}

CC BY-NC-ND 4.0

\section{REPOSITORY RECORD}

Sheng, Tian, Chuang Qiu, Xiao Lin, Wen-Feng Lin, and Shi-Gang Sun. 2020. "Insights into Ethanol Electrooxidation over Solvated Pt(1 0 0): Origin of Selectivity and Kinetics Revealed by DFT". Loughborough University. https://hdl.handle.net/2134/12811724.v1. 


\title{
Insights into ethanol electro-oxidation over solvated $\operatorname{Pt}(100)$ :
} origin of selectivity and kinetics revealed by DFT

\author{
Tian Sheng, ${ }^{* a}$ Chuang Qiu, ${ }^{\text {a } X i a o ~ L i n, ~}{ }^{\mathrm{b}}$ Wen-Feng Lin, ${ }^{* \mathrm{c}}$ Shi-Gang Sun*d \\ ${ }^{a}$ College of Chemistry and Materials Science, Anhui Normal University, Wuhu, \\ 241000, P. R. China. \\ ${ }^{b}$ Department of Chemical Engineering and Biotechnology, University of Cambridge, \\ Cambridge, CB3 OAS, United Kingdom. \\ ${ }^{c}$ Department of Chemical Engineering, Loughborough University, Loughborough, \\ Leicestershire, LE11 3TU, United Kingdom. \\ ${ }^{d}$ State Key Laboratory of Physical Chemistry of Solid Surfaces, College of Chemistry \\ and Chemical Engineering, Xiamen University, Xiamen, 361005, P. R. China.
}


*Corresponding authors.

E-mail addresses: tsheng@ahnu.edu.cn; w.lin@lboro.ac.uk; sgsun@xmu.edu.cn

Keywords: electrocatalysis; ethanol fuel cell; platinum; density functional theory; heterogeneous catalysis; 


\section{Introduction}

Fuel cells are promising clean energy technologies owing to their high energy efficiency and low carbon emission. Among the various types of fuel cells, direct ethanol fuel cells (DEFCs) are particularly attractive for transportation and portable applications because they have the advantage of direct use of liquid ethanol as the fuel, making them comparatively more convenient and with a much higher energy density than hydrogen or even methanol.[1-3] Furthermore, ethanol can be produced from renewable bio-feedstocks, as a carbon-neutral energy source. However, the large-scale implementation of DEFCs has been hindered by the slow kinetics for ethanol oxidation reactions on anodes. The ideal anodic reaction in DEFCs is the complete oxidation of ethanol to $\mathrm{CO}_{2}$ with the transfer of the maximum twelve electrons per ethanol molecule $\left(\mathrm{C}_{2} \mathrm{H}_{5} \mathrm{OH}+3 \mathrm{H}_{2} \mathrm{O}\right.$ $\left.\rightarrow 2 \mathrm{CO}_{2}+12 \mathrm{H}^{+}+12 \mathrm{e}^{-}\right)$. However, in practice the predominant partial oxidation of ethanol to acetic acid with the transfer of only four electrons $\left(\mathrm{C}_{2} \mathrm{H}_{5} \mathrm{OH}+\mathrm{H}_{2} \mathrm{O}\right.$ $\rightarrow \mathrm{CH}_{3} \mathrm{COOH}+4 \mathrm{H}^{+}+4 \mathrm{e}^{-}$) occurs in most reported catalytic systems.[1-6] To understand the complex surface reactions in the DEFCs, the surface structures of well-defined platinum electrodes have been extensively investigated in past years by using various single crystal planes and well-faceted nanoparticles as model catalysts.[7-9] Regarding the structure-reactivity relationship, it was found that the $\operatorname{Pt}(100)$ surface experimentally displays both a higher activity and a higher poisoning rate than $\operatorname{Pt}(111)$ and $\operatorname{Pt}(110)$. [8, 9]

Despite much theoretical progress in understanding how the surface structures of Pt and Pt-based catalysts may influence ethanol electro-oxidation reactions in terms of both activity and selectivity, most results reported so far have been based on calculations under vacuum conditions without considering the aqueous environment, resulting in a significant gap in relation to real DEFC systems; as such the data obtained under vacuum conditions may not be so relevant to real electrochemical interfaces.[10-13] The explicit inclusion of the solvent water molecules may influence the absolute energetics or revise the presented reaction 
mechanisms. Sakong et al. reported that solvents could stabilize the reaction intermediates in methanol oxidation containing hydrophilic groups using an implicit solvent model.[14] For catalytic reactions at electrodes, incorporating in the modelling the fluctuations and reorganization of water molecules around the reacting chemical species is a grand challenge. Nevertheless, time consuming but high accurate $a b$ initio molecular dynamics (MD) simulation based on density functional theory (DFT) now can precisely evaluate free energies of aqueous reactions by sampling solvent molecules at a given temperature.[15-18] Herron et al. concentrated on the role of solvents and electrode potentials on the energetics of the first proton transfer in methanol electro-oxidation on $\operatorname{Pt}(111)$ as a model surface by ab initio MD simulations.[18]

The reaction mechanisms of ethanol electro-oxidation are much more complex than those of methanol electro-oxidation due to the varieties of intermediates, especially involving the $\mathrm{C}-\mathrm{C}$ bond breaking process. The latter is a significant issue in utilization of ethanol in fuel cells. Searching for efficient catalysts for ethanol electro-oxidation with both high activity and high $\mathrm{CO}_{2}$ selectivity at low overpotentials is the most critical task for developing DEFCs. For the rational design of improved catalysts for DEFCs, a comprehensive understanding of ethanol electro-oxidation mechanisms in aqueous surroundings at atomic and free-energy levels is vital to identify the key intermediates, the rate-determining step and the main obstacles. Obtaining these critical data from theoretical calculations can effectively guide the design and synthesis of new catalysts.

In this work, the ethanol electro-oxidation mechanisms on solvated $\operatorname{Pt}(100)$ electrode were systematically investigated using constrained ab initio MD simulations. These cutting-edge computations reveal comprehensively the whole catalytic cycle, elucidating both the thermodynamics and kinetics of the process of going from ethanol to acetic acid and $\mathrm{CO}_{2}$. It was found that ethanol decomposition rates are sufficiently high, but the reaction rates of further oxidation of intermediates into final products are 
extremely slow, causing rapid poisoning of surface sites and seriously limiting the overall ethanol oxidation efficiency.

\section{Computational methods}

All calculations were carried out in the VASP code using the PerdewBurke-Ernzerhof (PBE) functional of exchange-correlation and the projectoraugmented-wave pseudopotentials.[19-22] Van der Waals (vdW) interactions were considered using D3 dispersion with zero damping.[23] The water/Pt(100) interface model comprises a four-layer $\mathrm{Pt}(100)$ slab with $64 \mathrm{Pt}$ atoms and 48 water molecules with the density of $1 \mathrm{~g} \mathrm{~cm}^{-3}$ (Figure 1), which is kept constant during the MD simulations. A vacuum layer of $6 \AA$ was inserted above the water layer. The cut-off energy was set as $400 \mathrm{eV}$ and a gamma Monkhorst-Pack kpoint mesh was used. The reaction free energies were evaluated by constrained ab initio MD simulations and thermodynamic integrations.[15] At first, 15 ps (a considerable time) of MD simulations were performed to equilibrate each initial state in elementary steps within the canonical (NVT) ensemble at $300 \mathrm{~K}$ ( $1 \mathrm{fs}$ per step). For each state (per $0.1 \AA$ ) along each reaction path, a MD simulation was run for 6 ps to collect 6000 samples. The time-averaged interatomic force from the last 1000 samples was utilized for integrations along the reaction path. All free energy profiles for the elementary steps with key structures are shown in the supporting information (Figures S1-19).

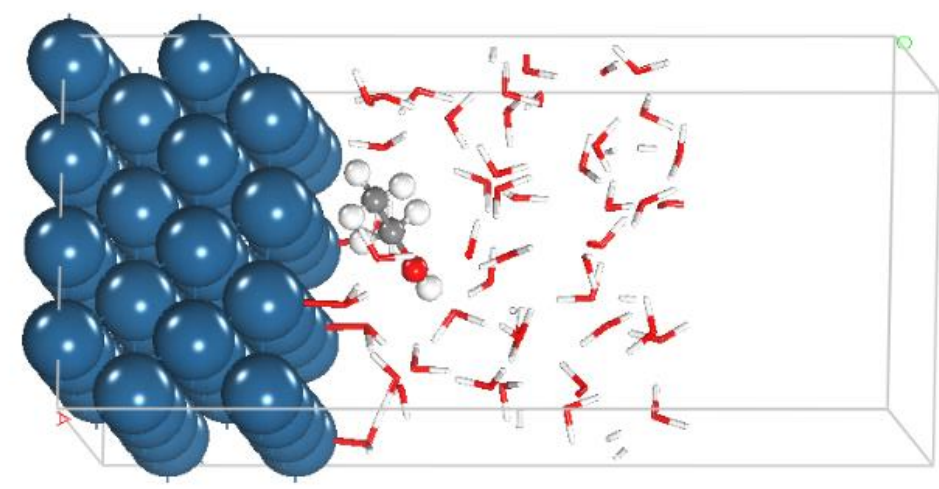


Figure 1. Model of the water/Pt(100) interface including 48 interfacial water molecules presented by the stick model and one ethanol molecule by the ball-stick model. Blue: Pt; red: O; grey: C; white: H. (The same colours are used throughout the paper.)

\section{Results}

The reaction mechanisms of ethanol electro-oxidation may be divided into two parts: the first part is ethanol decomposition to surface intermediates $\left(\mathrm{CH}_{3} \mathrm{CO}^{*}\right.$, $\left.\mathrm{CH}^{*}, \mathrm{CO}^{*}\right)$ and the second one is further oxidation of intermediates into products of acetic acid and/or $\mathrm{CO}_{2}$, whilst also generating free surface sites. Figure 2a shows the free energy profiles for ethanol decomposition over the solvated $\operatorname{Pt}(100)$ electrode, and Figure $2 \mathrm{~b}$ presents the structures of intermediates so formed. The reaction energies and kinetic barriers are listed in Table 1. Note that the ethanol electro-oxidation usually take place under strong acid or alkaline conditions which may play crucial roles on reaction mechanisms. Due to the limitation of computational cost, we only consider the neutral solution using water molecules only. The systematic investigation of $\mathrm{pH}$ effects is important but still a huge challenge within explicit water molecules.

\section{1. $\mathrm{CH}_{3} \mathrm{CO}^{*}$ formation}

One ethanol molecule initially placed on the surface was found to desorb into solution spontaneously after several ps in MD simulations. The $\mathrm{OH}$ group in ethanol was solvated by the surrounding water molecules $\left(\mathrm{CH}_{3} \mathrm{CH}_{2} \mathrm{OH}_{\mathrm{aq}}\right.$ in Figure $2 b$ ) that is similar to the situation of methanol on solvated $\operatorname{Pt}(111),[15]$ suggesting that water molecules can stabilize the $\mathrm{OH}$ group and thus reduce its possibility to react with the metal surface. The solvated ethanol can then readsorb onto the surface and once there it may be activated by the $\alpha-\mathrm{C}-\mathrm{H}$ bond cleavage with a free energy barrier of $0.46 \mathrm{eV}$ to yield $\mathrm{CH}_{3} \mathrm{CHOH}^{*}$ on surface; this step is exothermic by $-0.19 \mathrm{eV}$ following the Eley-Rideal mechanism (Figure S2). By overcoming a barrier of $0.19 \mathrm{eV}, \mathrm{CH}_{3} \mathrm{CHOH}^{*}$ breaks the second $\alpha-\mathrm{C}-\mathrm{H}$ 
bond to produce $\mathrm{CH}_{3} \mathrm{COH}^{*}$ at the top site with an $\mathrm{H}$-down (OH group) configuration (Figure $\mathrm{S} 3$ ). $\mathrm{CH}_{3} \mathrm{COH}^{*}$ is another unstable intermediate due to the $\mathrm{O}-\mathrm{H}$ bond dissociation barrier being only $0.15 \mathrm{eV}$ to generate $\mathrm{CH}_{3} \mathrm{CO} *$ (Figure S4).

\subsection{C-C bond breaking}

The $\mathrm{C}-\mathrm{O}$ bond in $\mathrm{CH}_{3} \mathrm{CO}^{*}$ prefers to be parallel to the $\mathrm{Pt}(100)$ surface through one C-Pt bond and one O-Pt bond $\left(\mathrm{CH}_{3} \mathrm{CO} *\right.$ in Figure $\left.2 \mathrm{~b}\right)$. For the formation of $\mathrm{CH}_{2} \mathrm{CO} *, \mathrm{CH}_{3} \mathrm{CO}^{*}$ diffuses to the top position firstly $\left(\mathrm{CH}_{3} \mathrm{CO}_{\mathrm{t}} *\right.$ in Figure $2 \mathrm{~b}$ ) and then breaks the $\beta-\mathrm{C}-\mathrm{H}$ bond. The migration of $\mathrm{CH}_{3} \mathrm{CO}^{*}$ to the top position requires only a small energy of $0.24 \mathrm{eV}$ to break the O-Pt surface bond (Figure S5). The latter explains why the $\mathrm{C}-\mathrm{O}$ bond in $\mathrm{CH}_{3} \mathrm{CO} *$ prefers to bond to the surface rather than being solvated by interfacial water molecules. Afterwards, the $\beta-\mathrm{C}-\mathrm{H}$ bond breaking is exothermic by $-0.25 \mathrm{eV}$ with a barrier of $0.41 \mathrm{eV}$ (Figure S6). Thus, the overall barrier for $\mathrm{CH}_{3} \mathrm{CO} *$ decomposition to $\mathrm{CH}_{2} \mathrm{CO} *$ is $0.65 \mathrm{eV}$ $(0.24 \mathrm{eV}$ for the position migration and $0.41 \mathrm{eV}$ for the bond breaking) and the reaction energy is $-0.01 \mathrm{eV}$. Surface $\mathrm{CH}_{2} \mathrm{CO}^{*}$ is active for further losing its hydrogen to form $\mathrm{CHCO}^{*}$ with a minor barrier of $0.17 \mathrm{eV}$ (Figure S7) rather than breaking its $\mathrm{C}-\mathrm{C}$ bond with a higher barrier of $0.81 \mathrm{eV}$ (Figure S8). CHCO* can further break its $\mathrm{C}-\mathrm{C}$ bond to form hollow $\mathrm{CH}^{*}$ and bridge $\mathrm{CO}^{*}$ with a barrier of $0.70 \mathrm{eV}$; this elementary step is highly exothermic of $-0.58 \mathrm{eV}$ (Figure S9).

All elementary steps for ethanol decomposition are reasonably facile in energetics (overcoming a barrier of $0.70 \mathrm{eV}$ or below), suggestive of a fast decomposition rate on solvated $\mathrm{Pt}(100)$ at room temperature. The calculated overall barrier for $\mathrm{CH}_{3} \mathrm{CO}^{*}$ formation (that is the ethanol partial oxidation pathway) is $0.46 \mathrm{eV}$, and that for $\mathrm{C} 1$ species formation (including $\mathrm{C}-\mathrm{C}$ bond cleavage in the ethanol complete oxidation pathway) is $0.70 \mathrm{eV}$, confirming that the rate limiting step is the $\mathrm{C}$ - $\mathrm{C}$ bond splitting process in ethanol decomposition.[12] 
(a)
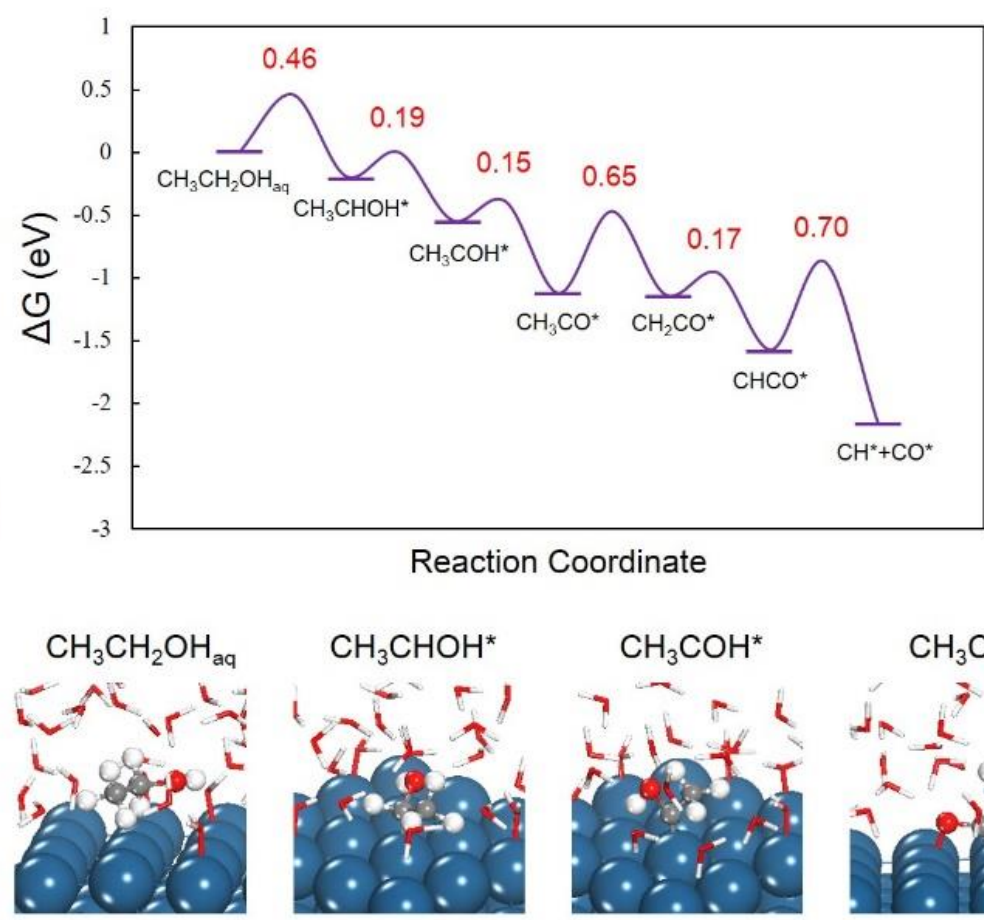

$\mathrm{CH}_{3} \mathrm{CO}_{\mathrm{t}}{ }^{*}$

$\mathrm{CH}_{2} \mathrm{CO}^{*}$

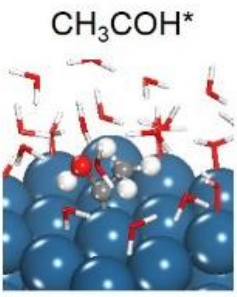

$\mathrm{CHCO}^{*}$
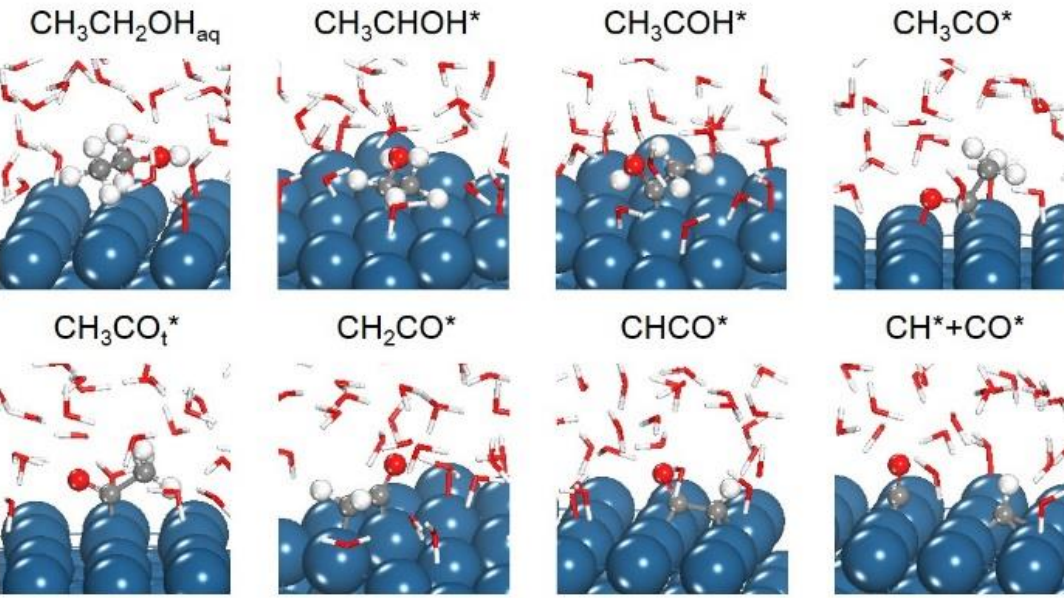

$\mathrm{CH}^{*}+\mathrm{CO}^{*}$

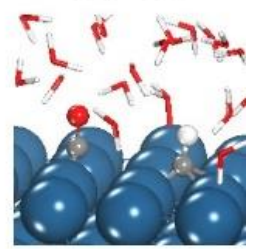

Figure 2. (a) Free energy profiles for ethanol decomposition over the solvated $\mathrm{Pt}(100)$ surface to $\mathrm{C} 1$ species with reaction barriers (in eV). (b) Snapshots of intermediates obtained from ab initio MD simulations. The interfacial water molecules were presented by the stick model.

\section{3. $\mathrm{CH}_{3} \mathrm{CO}^{*}$ oxidation}

After studying the initial ethanol decomposition steps, we concentrated on the oxidative processes of intermediates derived from ethanol decomposition; the oxidation reactions require the participation of surface $\mathrm{OH}^{*}$ species as oxidants which can be produced from water dissociation. Interestingly, in contrast to the insensitive reactivity of the $\mathrm{C}-\mathrm{H}$ and $\mathrm{C}-\mathrm{C}$ bond dissociation over the Pt surface with regards to the presence of water, the $\mathrm{C}-\mathrm{O}$ bond association would be easily 
affected by the aqueous environment due to the negatively charged $\mathrm{O}$ atom. The three relevant intermediates oxidation reactions have been calculated, these are $\mathrm{CH}_{3} \mathrm{CO}^{*}$ to acetic acid, $\mathrm{CH}^{*}$ to $\mathrm{CO}^{*}$, and $\mathrm{CO}^{*}$ to $\mathrm{CO}_{2}$. It has been found that water could readily dissociate to $\mathrm{OH}^{*}$ and $\mathrm{H}^{*}$ on $\mathrm{Pt}(100)$, having a downhill energy of $-0.19 \mathrm{eV}$ with a barrier of $0.39 \mathrm{eV}$ (Figure S1), which indicates that the $\mathrm{Pt}(100)$ surface has the ability to activate water to form $\mathrm{OH}^{*}$ without applying extra electrode potentials. Solvated $\mathrm{OH}^{*}$ was stable at the top site that is different from the preferred bridge site of $\mathrm{OH}^{*}$ on $\mathrm{Pt}(100)$ in vacuum. It is noted that we have not added or removed any electrons in our theoretical model; such a neutral solvated $\mathrm{Pt}(100)$ system thus may be close to the condition at the potential of zero charge $(\sim 0.4 \mathrm{~V})$. At this potential, the water dissociation can take place to somewhat extent, however, the exact coverage of $\mathrm{H}^{*}$ and $\mathrm{OH}^{*}$ were not considered.

Figure 3 presents the process of $\mathrm{CH}_{3} \mathrm{CO}^{*}$ being oxidized by $\mathrm{OH}^{*}$ to produce acetic acid. It was found that the production of acetic acid is mainly prohibited by thermodynamics $(\Delta \mathrm{G}=0.45 \mathrm{eV})$, although the overall barrier $(0.60 \mathrm{eV}$, the free energy difference between $\mathrm{CH}_{3} \mathrm{CO}^{*}+\mathrm{OH}^{*}$ and the transition state from $\mathrm{CH}_{3} \mathrm{COOH}^{*}$ to $\mathrm{CH}_{3} \mathrm{COOH}_{t} *$ in Figure $3 \mathrm{a}$ ) is kinetically feasible. The C-O bond coupling barrier between $\mathrm{CH}_{3} \mathrm{CO}^{*}$ and $\mathrm{OH}^{*}$ to form $\mathrm{CH}_{3} \mathrm{COOH}^{*}$ is only 0.53 $\mathrm{eV}$, but this step is endothermic by $0.35 \mathrm{eV}$ (Figure S10). Moreover, the C-O bond making does not induce a concurrent Pt-C bond breaking. Instead, the newly formed $\mathrm{CH}_{3} \mathrm{COOH}^{*}$ (Figure $3 \mathrm{~b}$ ) adsorbs on the surface with two O-Pt bonds and one C-Pt bonds being formed. It needs to overcome a barrier of 0.25 $\mathrm{eV}$ to break the $\mathrm{C}-\mathrm{Pt}$ bond to form $\mathrm{CH}_{3} \mathrm{COOH}_{\mathrm{t}}$ (Figure $3 \mathrm{~b}$ ) for decreasing the bonding strength of $0.06 \mathrm{eV}$ between $\mathrm{CH}_{3} \mathrm{COOH}^{*}$ and surface (Figure S11). $\mathrm{CH}_{3} \mathrm{COOH}_{\mathrm{t}}$ * bonds weakly to the surface via one $\mathrm{O}$ atom in the $\mathrm{OH}$ group with a small adsorption energy of $-0.04 \mathrm{eV}$ (Figure S12). We also found that the deprotonation of $\mathrm{CH}_{3} \mathrm{COOH}_{\mathrm{t}}$ * can occur to form bidentate $\mathrm{CH}_{3} \mathrm{COO}^{*}(\Delta \mathrm{G}=-$ $0.06 \mathrm{eV}$ ) which is more stable than acetic acid on surface with a negligible barrier 
(a)

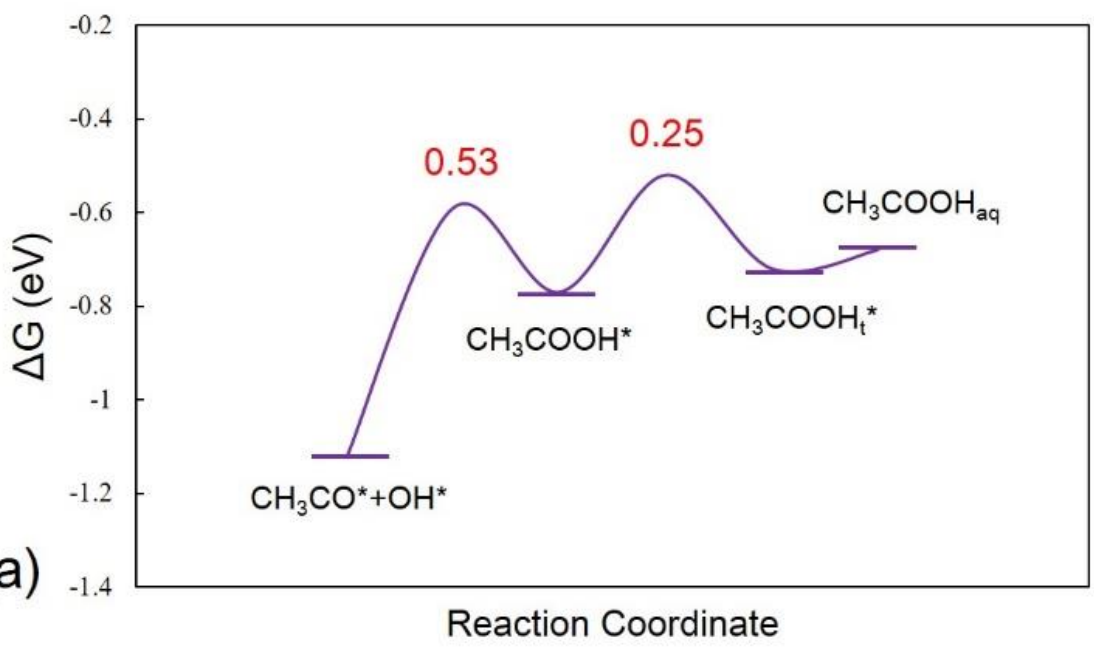

(b)

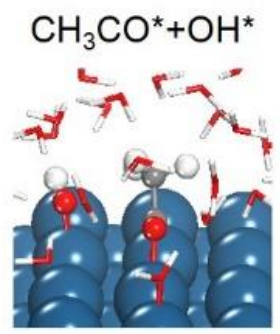

TS
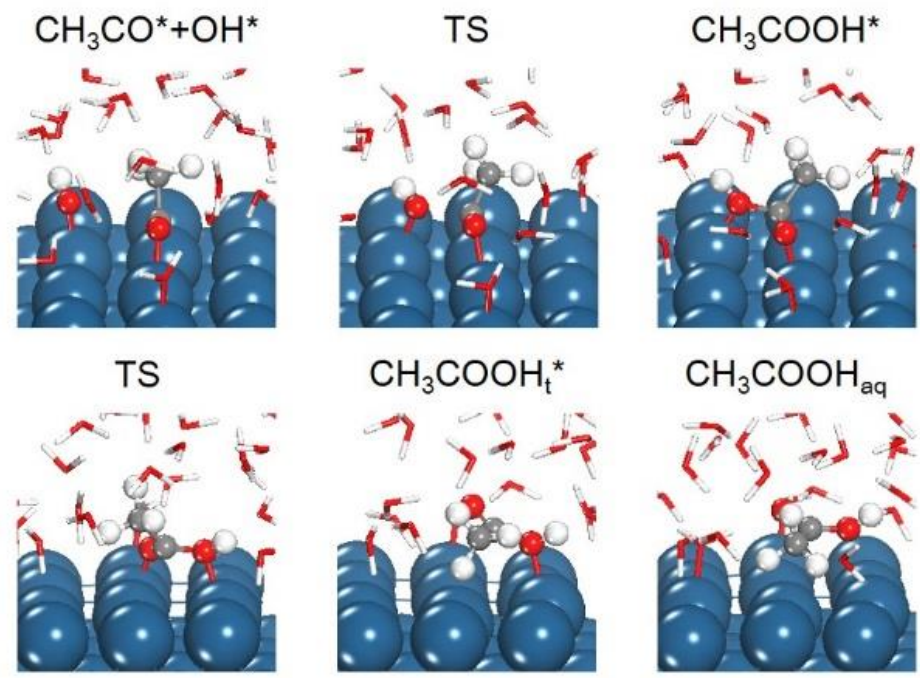

Figure 3. (a) Free energy profiles for $\mathrm{CH}_{3} \mathrm{CO}^{*}$ oxidation reaction over the solvated $\mathrm{Pt}(100)$ surface with reaction barriers (in eV). (b) Snapshots of of intermediates and transition states obtained from $a b$ initio MD simulations.

\section{4. $\mathrm{CH} *$ oxidation}

$\mathrm{CH}^{*}$ oxidized by surface $\mathrm{OH}^{*}$ to form $\mathrm{CO}^{*}$ is energetically feasible; this process is exothermic of $-1.13 \mathrm{eV}$ with the overall barrier of $0.91 \mathrm{eV}$ (the energy difference between $\mathrm{CH}^{*}+\mathrm{OH}^{*}$ and the transition state from co-adsorbed $\mathrm{CH}^{*}+$ 
$\mathrm{OH}^{*}$ to $\mathrm{CHOH}^{*}$ in Figure 4a), implying that $\mathrm{CH}^{*}$ can be converted to $\mathrm{CO}^{*}$ by $\mathrm{OH}^{*}$, although the conversion rate is not very fast at room temperature (Figure S14). At first, one hollow $\mathrm{CH}^{*}$ occupies four Pt surface atoms and a top $\mathrm{OH}^{*}$ stays at another free $\mathrm{Pt}$ atom $\left(\mathrm{CH}^{*}+\mathrm{OH}^{*}\right.$ in Figure $\left.4 \mathrm{~b}\right)$. The distance between $\mathrm{O}$ and $\mathrm{C}$ atoms can be shortened, with $\mathrm{OH}^{*}$ moving to one of the four Pt atoms initially occupied by $\mathrm{CH}^{*}$, thus leading to a repulsive interaction of $0.26 \mathrm{eV}$ with the sharing of a same Pt atom (co-adsorption state in Figure 4b). Next, with further overcoming a barrier of $0.65 \mathrm{eV}$, the $\mathrm{C}-\mathrm{O}$ bond formation results in forming $\mathrm{CHOH}^{*}$. This step is slightly exothermic, by $-0.16 \mathrm{eV}$. Afterwards, $\mathrm{CHOH}^{*}$, with a tiny energy barrier of $0.06 \mathrm{eV}$, rapidly generates $\mathrm{CHO}^{*}$ with the release of a proton and electron couple (Figure S15). Further decomposition of CHO* to $\mathrm{CO} *$ is very easy both thermodynamically and kinetically, being highly exothermic, releasing $-0.91 \mathrm{eV}$, and a low barrier of $0.15 \mathrm{eV}$ (Figure S16). Experiments only found the conversion of $\mathrm{CH}^{*}$ to $\mathrm{CO}^{*}$ only above $0.4 \mathrm{~V}$. It is suggested two possible reasons: (i) at very low potentials, ethanol dissociation would produce amounts of surface $\mathrm{H}^{*}$, which may convert $\mathrm{CH}^{*}$ into $\mathrm{CH}_{4}$.[24] (ii) The increase of electrode potentials can decrease the $\mathrm{H}^{*}$ coverage while increase the $\mathrm{OH}^{*}$ coverage. The lower $\mathrm{H}^{*}$ coverage can suppress the reduction of $\mathrm{CH}^{*}$ and the higher $\mathrm{OH}^{*}$ coverage may facilitate the oxidation of $\mathrm{CH}^{*}$. 
(a)

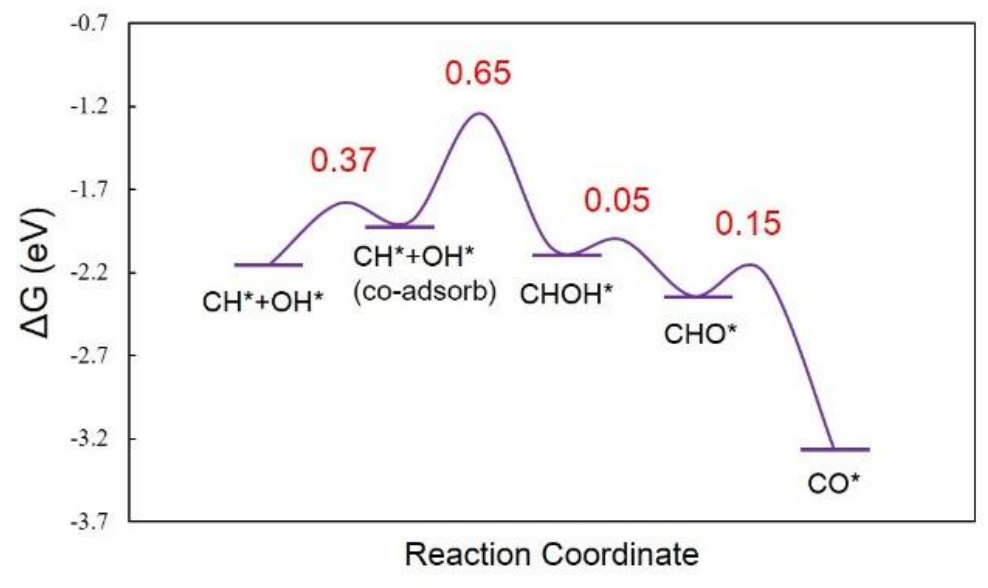

(b)

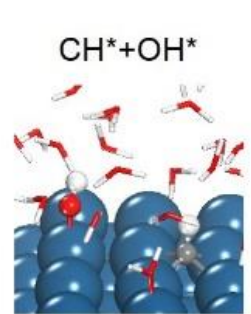

$\mathrm{CHOH}^{\star}$

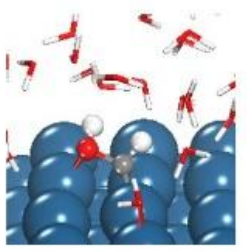

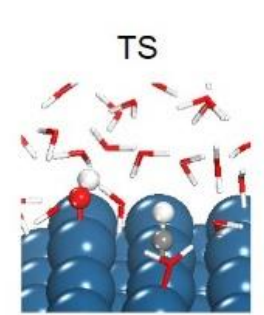

$\mathrm{CHO}^{*}$

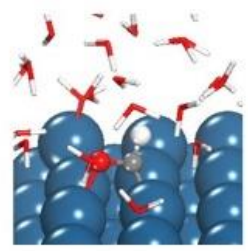

$\mathrm{CH}^{*}+\mathrm{OH}^{*}$

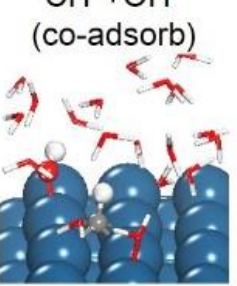

TS

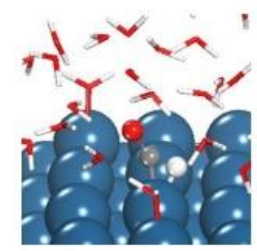

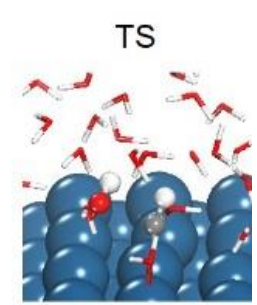

$\mathrm{CO}^{*}$

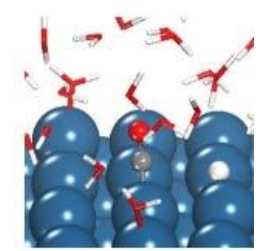

Figure 4. (a) Free energy profiles for $\mathrm{CH}^{*}$ oxidation reaction over the solvated $\mathrm{Pt}(100)$ electrode with the reaction barriers (in eV). (b) Snapshots of intermediates and transition states obtained from $a b$ initio MD simulations.

\subsection{CO* oxidation}

In contrast to the easy $\mathrm{CH}^{*}$ oxidation, further oxidation of surface $\mathrm{CO}^{*}$ by $\mathrm{OH}^{*}$ was found to be significantly inhibited from both the thermodynamic and kinetic points of view, as shown in Figure 5a. The coupling barrier between $\mathrm{CO}^{*}$ and $\mathrm{OH}^{*}$ to yield $\mathrm{COOH}^{*}$ is as high as $1.04 \mathrm{eV}$ and the reaction energy is uphill, costing $0.68 \mathrm{eV}$ (Figure $\mathrm{S} 17$ ). If the $\mathrm{COOH}^{*}$ is produced, it is rather unstable and can be readily converted to $\mathrm{CO}_{2} *$ with the loss of a proton and electron couple. The latter step is exothermic, releasing $-0.57 \mathrm{eV}$ and with a tiny proton transfer barrier of $0.03 \mathrm{eV}$ (Figure $\mathrm{S} 18$ ). The formed $\mathrm{CO}_{2} *$ prefers to stay on the interface, 
(a)

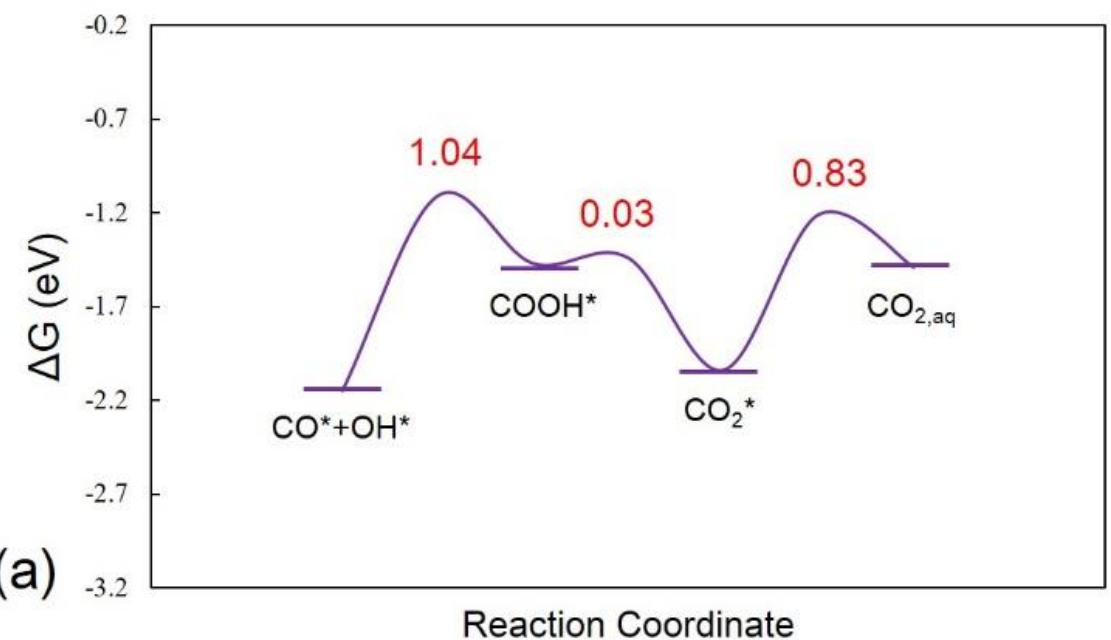

(b)
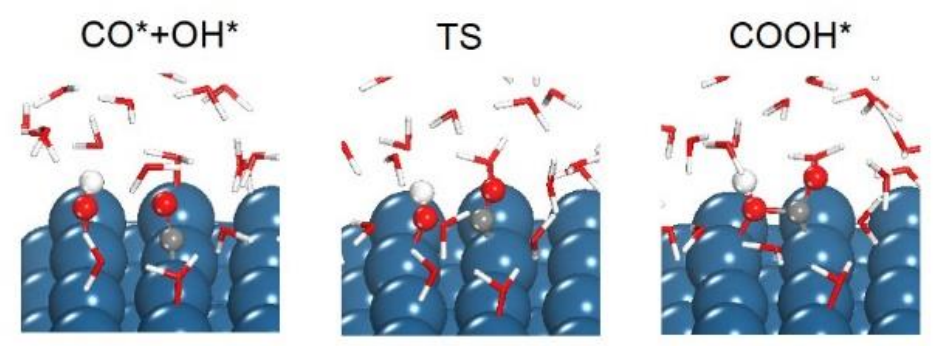

$\mathrm{CO}_{2}{ }^{*}$

TS
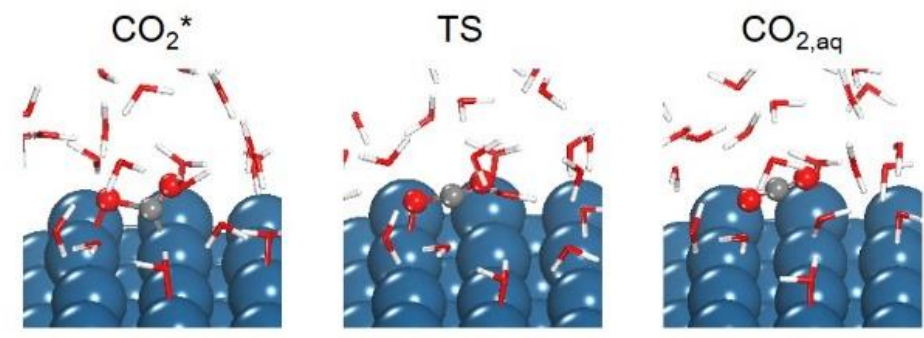
Figure 5. (a) Free energy profiles for $\mathrm{CO}^{*}$ oxidation reaction over the solvated $\operatorname{Pt}(100)$ surface with the reaction barriers (in $\mathrm{eV}$ ). (b) Snapshots of intermediates and transition states obtained from $a b$ initio MD simulations.

Table 1. Calculated free energy barriers $\left(E_{a}\right)$ and reaction free energies $(\Delta G)$ in eV of elementary steps in ethanol electro-oxidation over the solvated $\operatorname{Pt}(100)$ electrode.

\begin{tabular}{|c|c|c|}
\hline surface reactions & $\mathbf{E}_{\mathbf{a}}$ & $\Delta \mathbf{G}$ \\
\hline $\mathrm{C}_{2} \mathrm{H}_{5} \mathrm{OH} \rightarrow \mathrm{CH}_{3} \mathrm{CHOH}^{*}$ & 0.46 & -0.19 \\
\hline $\mathrm{CH}_{3} \mathrm{CHOH}^{*} \rightarrow \mathrm{CH}_{3} \mathrm{COH}^{*}$ & 0.19 & -0.35 \\
\hline $\mathrm{CH}_{3} \mathrm{COH}^{*} \rightarrow \mathrm{CH}_{3} \mathrm{CO}^{*}$ & 0.15 & -0.58 \\
\hline $\mathrm{CH}_{3} \mathrm{CO}^{*} \rightarrow \mathrm{CH}_{3} \mathrm{CO}_{\mathrm{t}}^{*}$ & I & 0.24 \\
\hline $\mathrm{CH}_{3} \mathrm{CO}^{*} \rightarrow \mathrm{CH}_{2} \mathrm{CO}^{*}$ & 0.41 & -0.25 \\
\hline $\mathrm{CH}_{2} \mathrm{CO}^{*} \rightarrow \mathrm{CHCO}^{*}$ & 0.17 & -0.44 \\
\hline $\mathrm{CH}_{2} \mathrm{CO}^{*} \rightarrow \mathrm{CH}_{2} *+\mathrm{CO}^{*}$ & 0.81 & -0.48 \\
\hline $\mathrm{CHCO}^{*} \rightarrow \mathrm{CH}^{*}+\mathrm{CO}^{*}$ & 0.70 & -0.58 \\
\hline $\mathrm{H}_{2} \mathrm{O}^{*} \rightarrow \mathrm{OH}^{*}+\mathrm{H}^{*}$ & 0.39 & -0.19 \\
\hline $\mathrm{CH}_{3} \mathrm{CO}^{*}+\mathrm{OH}^{*} \rightarrow \mathrm{CH}_{3} \mathrm{COOH}^{*}$ & 0.53 & 0.35 \\
\hline
\end{tabular}




\section{Discussion}

The strong bonding between carbon-containing intermediates and the surface can lead to high ethanol decomposition activity because of the notable BronstedEvans-Polanyi (BEP) relations, but the intermediates derived from ethanol decomposition then have problems to in turn be further converted into products. It is thus reasonable to suggest that the optimum binding energies of intermediates on surface are critical in determining the total reactivity. For the improvement of ethanol electro-oxidation reaction efficiency, it is essential to balance the initial ethanol decomposition rates and the intermediates further oxidation rates, by finely tuning the binding energies of intermediates. These binding energies of intermediates, with regard to the $\mathrm{Pt}(100)$ electrode, are obviously too strong, resulting in the slow kinetics in the overall oxidation process. Therefore, we suggest that weakening the surface affinity towards intermediates adsorption by, for example, engineering the surface structures via alloying, could improve the whole ethanol electro-oxidation activity. Interestingly, it has been evidenced experimentally on methanol system, e.g., the 
$\{100\}$-faceted $\mathrm{Pt}_{3} \mathrm{Co}$ nanocubes with the weakened $\mathrm{CO}$ adsorption were reported to effectively enhance the methanol electro-oxidation rates.[25] Small $\mathrm{Pt}_{3} \mathrm{Co}$ nanoparticles with a Pt skin structure were also found to facilitate ethanol electrooxidation reactions with a reduced $\mathrm{CO}$ formation.[26]

Finally, to further ensure the calculation accuracy for such a multi-step reaction, we calculated the equilibrium potentials for the two products of ethanol oxidation, the partial oxidation product acetic acid and the full oxidation product $\mathrm{CO}_{2}$, respectively. According to the equilibrium of $\mathrm{H}^{+}+\mathrm{e}^{-} \rightarrow \mathrm{H}^{*}$ under standard hydrogen electrode (SHE) condition, we converted the binding free energy of $\mathrm{H}^{*}(-0.33 \mathrm{eV}$ in vacuum, without considering the solvation effects) on $\operatorname{Pt}(100)$ into the free energy of $\left(\mathrm{H}^{+}+\mathrm{e}^{-}\right)$under the SHE condition to calculate the theoretical equilibrium potentials. The completed energy profile is presented in Figure 6. The equilibrium potentials were calculated to be 0.076 $\mathrm{V}$ for acetic acid production and $0.103 \mathrm{~V}$ for $\mathrm{CO}_{2}$ production, which are close to the standard equilibrium values $\left(0.084 \mathrm{~V}\right.$ for acetic acid, $0.089 \mathrm{~V}$ for $\left.\mathrm{CO}_{2}\right)$, as listed in Table 2. Such small differences confirm that our calculations are reliable for descriptions of the energetic values in ethanol electro-oxidation reaction. 


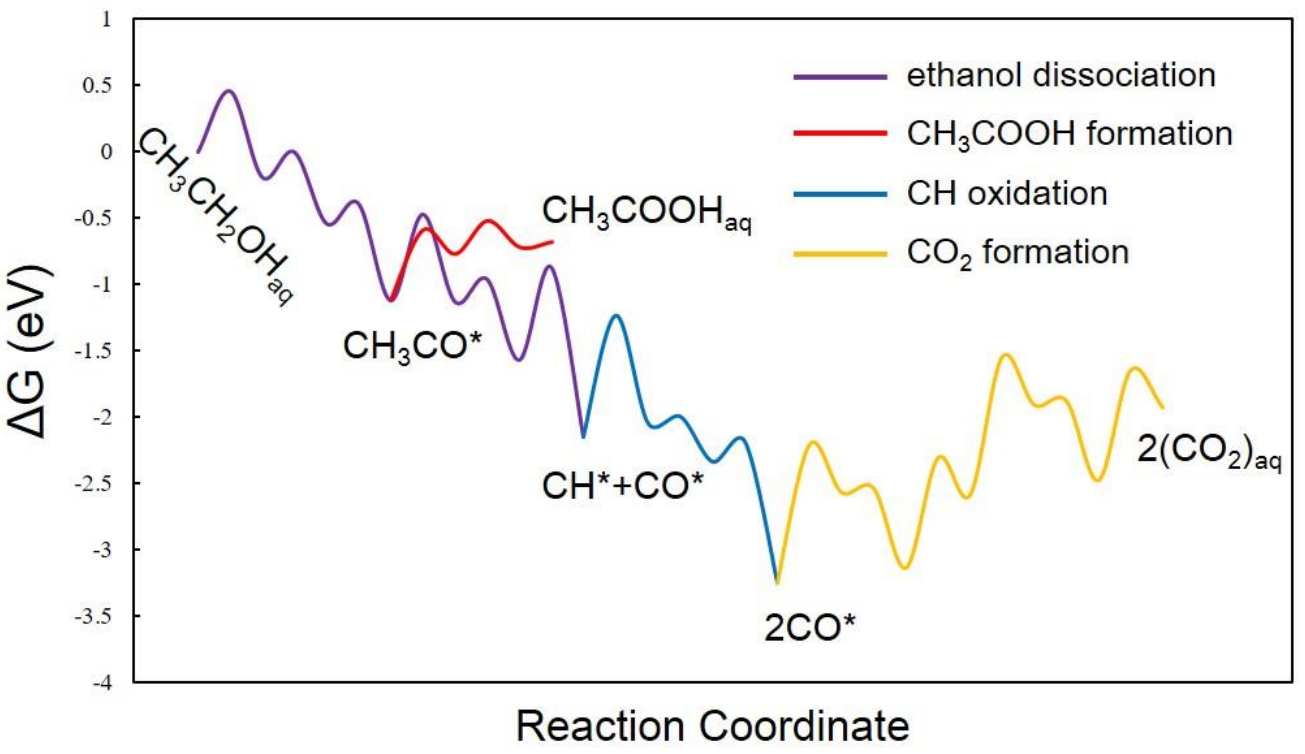

Figure 6. Complete free energy profile for ethanol electrooxidation reaction over the solvated Pt(100) electrode.

\section{Conclusions}

In summary, by performing constrained $a b$ initio MD simulations with the explicit aqueous environment, we have provided solid theoretical evidences that the $\operatorname{Pt}(100)$ electrode is rather active towards ethanol decomposition; the main bottleneck in controlling the overall ethanol electrooxidation reaction efficiency is further oxidation of the intermediates to final products. The origin of the slow kinetics in ethanol electro-oxidation on $\operatorname{Pt}(100)$ was thus identified to be the bonding between intermediates and the Pt surface being too strong. We have proposed that weakening the surface affinity towards adsorption of intermediates such as $\mathrm{CO}$, for example by engineering the surface structures via alloying, could improve the whole ethanol electro-oxidation activity. These findings are of general importance for understanding and solving the key issues surrounding the electro-oxidation of small organic molecules on Pt and Pt-based electrodes, and 


\section{Acknowledgements}

The financial support from the National Natural Science Foundation of China (21903001), Natural Science Foundation of Anhui Province (1908085QB58), the EPSRC (EP/I013229/1), and the Royal Society and the Newton Fund (NAF\R1\191294).

\section{References}

[1] E. Antolini, Catalysts for direct ethanol fuel cells, J. Power Sources 170 (2017) 112 .

[2] J. M, Jin, T. Sheng, X. Lin, R. Kavanagh, P. Hamer, P. Hu, C. Hardacre A. MartinezBonastre, J. Sharman, D. Thompsett, W. F. Lin, The origin of high activity but low $\mathrm{CO}_{2}$ selectivity on binary PtSn in the direct ethanol fuel cell, Phys. Chem. Chem. Phys. 16 (2014) 9432-9440.

[3] A. Rabis, P. Rodriguez, J. T. Schmidt, Electrocatalysis for polymer electrolyte fuel cells: recent achievements and future challenges, ACS Catal. 2 (2012) 864-890. 
[4] J. J. Linares, S. C. Zignani, T. de A. Rocha, E. R. Gonzalez, Ethanol oxidation on a high temperature PBI-based DEFC using $\mathrm{Pt} / \mathrm{C}, \mathrm{PtRu} / \mathrm{C}$ and $\mathrm{Pt} 3 \mathrm{Sn} / \mathrm{C}$ as catalysts, J. Appl. Electrochem. 43 (2013), 147-158

[5] B. Braunchweig, D. Hibbitts, M. Neurock, A. Wieckowski, Electrocatalysis: a direct alcohol fuel cell and surface science perspective, Catal. Today 202 (2013) 197-209.

[6] M. H. Shao, R. R. Adzic, Electrooxidation of ethanol on a Pt electrode in acid solutions: in situ ATR-SEIRAS study, Electrochim. Acta 50 (2005) 2415-2422.

[7] N. F. Yu, N. Tian, Z. Y. Zhou, T. Sheng, W. F. Lin, J. Y. Ye, S. Liu, H. B. Ma, S. G. Sun, Pd nanocrystals with continuously tunable high-index facets as a model nanocatalyst, ACS Catal, 9 (2019) 3144-3152.

[8] F. Colmati, G. Tremiliosi, E. R. Gonzalez, A. Berna, E. Herrero, J. M. Feliu, Surface structure effects on the electrochemical oxidation of ethanol on platinum single crystal electrodes, Faraday Discuss. 140 (2008) 379-397.

[9] S. C. S. Lai, M. T. M. Koper, The influence of surface structure on selectivity in the ethanol electro-oxidation reaction on platinum, J. Phys. Chem. Lett. 1 (2010) 11221125.

[10] H. F. Wang, Z. P. Liu, Comprehensive mechanism and structure-sensitivity of ethanol oxidation on platinum: New transition-state searching method for resolving the complex reaction network, J. Am. Chem. Soc. 130 (2008) 1099611004.

[11] R. Kavanagh, X. M. Cao, W. F. Lin, C. Hardacre, P. Hu, Origin of low $\mathrm{CO}_{2}$ selectivity on platinum in the direct ethanol fuel cell, Agnew. Chem. Int. Ed 51 (2012) $1572-1575$.

[12] T. Sheng, W. F. Lin, S. G. Sun, Elucidation of the surface structure-selectivity relationship in ethanol electro-oxidation over platinum by density functional theory, Phys. Chem. Chem. Phys. 18 (2016) 15501-15504.

[13] T. Sheng, W. F. Lin, C. Hardacre, P. Hu, Role of water and adsorbed hydroxyls on ethanol electrochemistry on Pd: new mechanism, active centers, and energetics for 
direct ethanol fuel cell running in alkaline medium, J. Phys. Chem. C 118 (2014) 57625772 .

[14] S. Sakong, A. Groß, The importance of the electrochemical environment in the electro-oxidation of methanol on Pt(111), ACS Catal. 6 (2016) 5575-5586.

[15] M. Sprik, G. Ciccotti, Free energy from constrained molecular dynamics, J. Chem. Phys. 109 (1998) 7737-7744.

[16] A. A. Hassanali, J. Cuny, V. Verdolino, M. Parrinello, Aqueous solutions: state of the art in ab initio molecular dynamics, Phil. Trans. R. Soc. A 372 (2014) 20120482. [17] D. Wang, T. Sheng, J. F. Chen, H. F. Wang, P. Hu, Identifying the key obstacle in photocatalytic oxygen evolution on rutile $\mathrm{TiO}_{2}$, Nat. Catal. 1 (2018) 291-299.

[18] J. A. Herron, Y. Morikawa, M. Mavrikakis, Ab initio molecular dynamics of solvation effects on reactivity at electrified interfaces, Proc. Natl. Acad. Sci. U. S. A. 113 (2016) E4937-E4945.

[19] G. Kresse, J. Hafner, Ab initio molecular dynamics for open-shell transition metals, Phys. Rev. B 48 (1993) 13115-13118.

[20] G. Kresse, J. Furthmuler, Efficient iterative schemes for ab initio total-energy calculations using a plane-wave basis set. Phys. Rev. B 54 (1996) 11169-11186.

[21] P. E. Blochl, Projector augmented-wave method, Phys. Rev. B 50 (1994) $17953-$ 17979.

[22]. J. P. Pedrew, K. Burke, M. Ernzerhof, Generalized gradient approximation made simple, Phys. Rev. Lett. 77 (1996) 3865-3868.

[23] S. Grimme, J. Antony, S. Ehrlich, H. Krieg, A consistent and accurate ab initio parametrization of density functional dispersion correction (DFT-D) for the 94 elements H-Pu, J. Chem. Phys. 132 (2010) 154104.

[24] S. C. S. Lai, M. T. M. Koper, Electro-oxidation of ethanol and acetaldehyde on platinum single-crystal electrodes, Faraday Discuss. 140 (2008) 399-416.

[25] Yang, H. Z. Zhang, J. Sun, K. Zou, S. Z. Fang, J. Y., Enhancing by Weakening: Electrooxidation of Methanol on Pt3Co and Pt Nanocubes, Agnew. Chem. Int. Ed 49 (2010) 6848-6851. 
[26] B. W. Zhang, T. Sheng, Y. X. Wang, X. M. Qu, J. M. Zhang, Z. C. Zhang, H. G. Liao, F. C. Zhu, S. X. Dou, Y. X. Jiang, S. G. Sun, Platinum-cobalt bimetallic nanoparticles with Pt skin for electro-oxidation of ethanol, ACS Catal. 7 (2017) 892895. 